\title{
Diaphyseal Radius Fracture Associated with Irreducible Head Dislocation. Case Report
}

\section{Fractura diafisaria de radio asociada a luxación irreductible de la cabeza. Relato de caso}

\author{
Alfredo Villar Blanco ${ }^{10}$ Patricia Gómez Barbero ${ }^{1 \oplus}$ María Del Sol Gómez Aparicio ${ }^{10}$ \\ Jose Ignacio Pérez Correa ${ }^{1}$ \\ 1 Orthopedic Surgery and Traumatology Service, Hospital \\ Universitario Doctor Peset, Valencia, Spain \\ Rev Iberam Cir Mano 2021;49(2):e155-e159. \\ Address for correspondence Alfredo Villar Blanco, Servicio de Cirugía \\ Ortopédica y Traumatología, Hospital Universitario Doctor Peset, \\ Avenida Gaspar Aguilar 90, Valencia, 46017, España \\ (e-mail: alfredoviblan.detec@gmail.com).
}

\begin{abstract}
Keywords

- radial head dislocation

- articular fracture

- radius fracture

- biceps tendon
\end{abstract}

\section{Resumen}

\section{Palabras Clave}

- luxación de la cabeza del radio

- fractura articular

- fractura del radio

- tendón del bíceps
Irreducible dislocation of the radial head is an extremely rare lesion, especially in an adult patient. We present a case of diaphyseal radius fracture associated with a posterior elbow dislocation and an irreducible radial head dislocation. After closed reduction of the elbow, we performed open reduction and ostheosynthesis of the radius, and the radial head remained irreducible. We finally found, surrounding the radius, the interposition of the insertion of the biceps, and, after extracting it, we performed the correct reduction of the radial head. Six months after the surgery, the patient presented a full articular balance, with no pain. We have not found any similar case in the literature.

La luxación no reductible de cabeza radial es una lesión extremadamente infrecuente, especialmente en el paciente adulto. Presentamos el caso de una fractura diafisaria de radio asociada a una luxación posterior de codo y a una luxación irreductible de la cabeza radial. Tras una reducción cerrada de codo, se realizó la reducción abierta y osteosíntesis de radio, permaneciendo irreductible la cabeza radial. Finalmente hallamos circundando al radio la interposición de la inserción del bíceps, y, tras la retirada de la misma, realizamos la correcta reducción de la cabeza radial. Seis meses tras la cirugía, el paciente presentaba un balance articular completo sin dolor. No hemos hallado en la literatura ningún caso similar.

\section{Introduction}

Elbow joint fractures are frequent injuries in the daily clinical practice. Occasionally, these fractures are associated with a dislocation, usually with severe ligamentous injuries to the surrounding structures.

received

June 30,2020

accepted

March 31, 2021
DOI https://doi.org/ $10.1055 / \mathrm{s}-0041-1731768$. ISSN 1698-8396.
Several publications ${ }^{1}$ in the literature describe and classify the most frequent patterns of elbow fractures and fracture-dislocations. One of the best-known injuries at this level are the Monteggia and Galeazzi fracture-dislocations. In 1822, Cooper was the first author to describe an isolated radial shaft fracture associated with a distal

(c) 2021. SECMA Foundation. All rights reserved.

This is an open access article published by Thieme under the terms of the Creative Commons Attribution-NonDerivative-NonCommercial-License, permitting copying and reproduction so long as the original work is given appropriate credit. Contents may not be used for commercial purposes, or adapted, remixed, transformed or built upon. (https://creativecommons.org/ licenses/by-nc-nd/4.0/)

Thieme Revinter Publicações Ltda., Rua do Matoso 170, Rio de Janeiro, RJ, CEP 20270-135, Brazil 
radioulnar joint dislocation. However, this injury was called the Galeazzi fracture-dislocation, referring to Ricardo Galeazzi, who described a series of 18 cases in 1934. In the Monteggia lesion, described by Giovanni Battista Monteggia in 1814 , a fracture of the proximal third of the ulna occurs together with a dislocation of the proximal radioulnar joint. Years later, in 1967, José Luís Bado described the most popular classification for this injury. The Bado classification stratifies these fracture-dislocations into four types based on the fracture site and the location of the radial head.

The present article describes the case of an adult patient with a radial shaft fracture associated with a posterior elbow dislocation plus proximal radioulnar dislocation. After closed reduction, an anteromedial dislocation of the radial head was evidenced; although this injury resembles those described by Bado, it is not within any classification, thus highlighting the importance of this case due to its rarity.

\section{Clinical Case}

A 70-year-old male patient presented to the Traumatology Emergency Service after a casual fall from his own height with trauma to the right upper limb. A physical examination revealed deformity and swelling of the forearm and elbow with disruption of the Nelaton triangle, pain, and functional impairment. The patient had no distal neurovascular abnormalities, and the distal radioulnar joint seemed stable. A radiological study revealed a posterior elbow dislocation associated with a diaphyseal fracture of the middle third of the radius and a proximal radioulnar dislocation. The posterior elbow dislocation was reduced, followed by immobilization with a posterior brachiopalmar splint. A control radiograph showed the reduction of the initial dislocation, in addition to a secondary displacement of the radial shaft fracture and an anteromedial dislocation of the radial head (-Figure 1).

In a delayed manner, the patient underwent surgery. Using an expanded Henry approach, open reduction and internal fixation of the radius shaft fracture were performed with a 7-hole, 3.5-mm locking compression plate (LCP, Synthes, Solothurn, Switzerland); the anatomical reduction of the fracture was confirmed by arthroscopy. Next, repeated maneuvers for closed reduction of the radial head were unsuccessful, leading to a Kaplan approach to the radial head. Several attempts for open reduction of the radial head were met with great resistance, with the radial head resuming its anteromedial dislocation when the posterolateral traction required for reduction was suspended. After carefully examining the field, we observed that the distal insertion of the biceps tendon was surrounding the radial neck in $360^{\circ}$, preventing the reduction (-Figure 2). Given these findings, the biceps tendon was reduced to its anatomical position, followed by an immediate, spontaneous reduction of the radial head. The elbow was explored, revealing stability at flexion-extension and pronation-supination. Finally, the lateral collateral ligament was repaired using three 3.5-mm harpoons. The ruptured capsule was also repaired, and correct joint congruence and elbow stability were verified on arthroscopy.

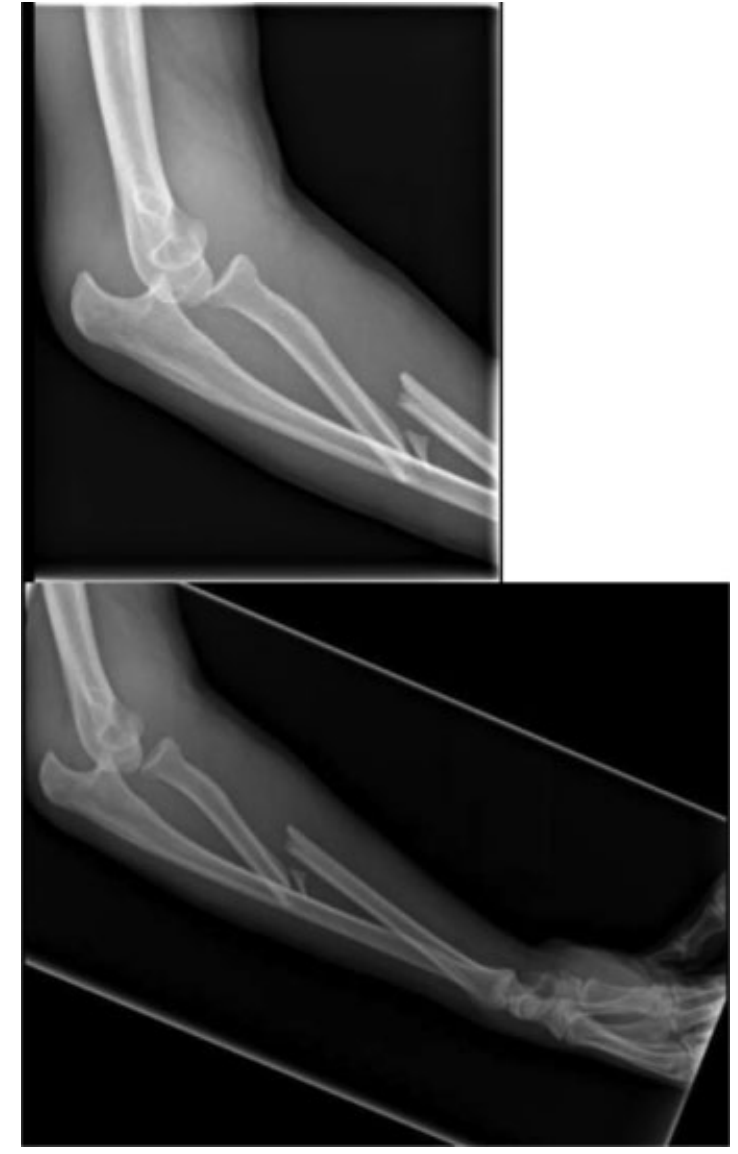

Fig. 1 Prereduction radiological images taken upon the arrival of the patient at the emergency room.

The rehabilitation protocol with active mobilization started after a ten-day immobilization period with a posterior brachiopalmar splint. Elbow movement was limited during the first 3 weeks, with a ligament orthosis locked at $-30^{\circ}$ of extension and $100^{\circ}$ of flexion. Three months after the injury, the patient had an active joint balance of $-5^{\circ}$ to $120^{\circ}$ of flexion-extension and complete pronation-supination ( - Figure 3 ), in addition to radiological consolidation of the fracture (-Figures 4 and $\mathbf{5}$ ).

\section{Discussion}

Posterior elbow dislocation is usually associated with an ulnar fracture with radial head dislocation, the so-called Monteggia fracture-dislocation. The association with a diaphyseal radius fracture is very infrequent, with few cases described in the literature. The first clinical case was published in 1929 by Valende; a second, very similar case was reported 30 years later by Beach and Hewson. ${ }^{1}$ Both cases were resolved with closed reduction of the elbow dislocation along with open reduction and osteosynthesis of the radius fracture. In addition, we found several case descriptions ${ }^{1,2}$ of patients with radial shaft fractures associated with radial head fractures, but with no elbow dislocation. There is no current validated classification that typifies the association of diaphyseal radial fracture and posterior dislocation of the elbow. Wong-Chung et al. $^{3}$ published a clinical case of a 


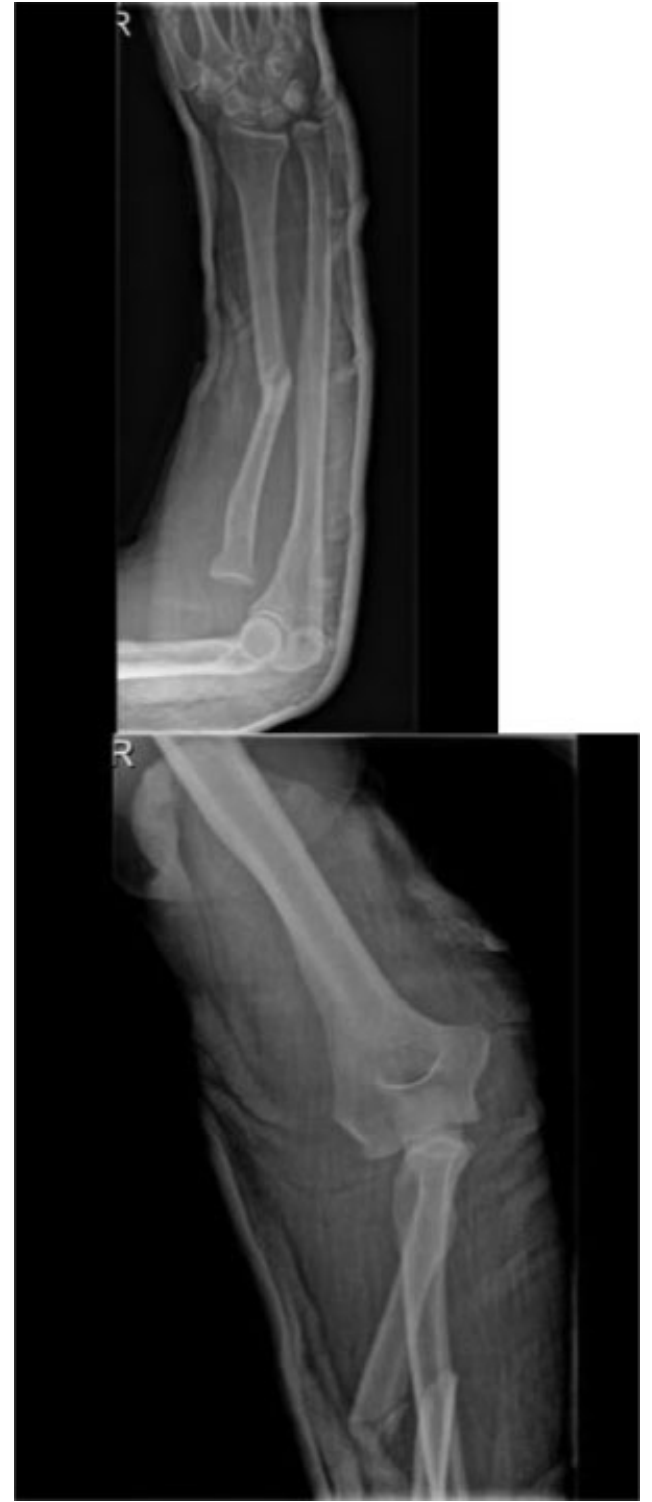

Fig. 2 (A) Radiograph of the fracture at the emergency room with anteroposterior and lateral cast.

patient with a distal radial fracture and posterior elbow dislocation, proposing it as a type- $\mathrm{V}$ injury per the Bado classification system. However, other authors do not agree with including this type of fracture among the Monteggialike injuries due to the lack of ulnar shaft fracture.

Referring to the injuries described in our case, Domingo et al. ${ }^{4}$ reported the clinical case of a patient in which the ruptured radial collateral ligament prevented the correct closed reduction of the radial head. However, we did not find in the literature any association like the one depicted here.

The literature does not describe a clear mechanism for this injury. Some authors, such as Osborne and Cotterill, ${ }^{5}$ advocate that this mechanism consists of a compressive axial force with the elbow slightly flexed, while others, such as Soon et al., ${ }^{6}$ defend that this injury results from a fall with a hyperextended arm, radial deviated wrist, and hyperpronated forearm. Therefore, after the present review, we assume that, in our case, what happened was a low-energy

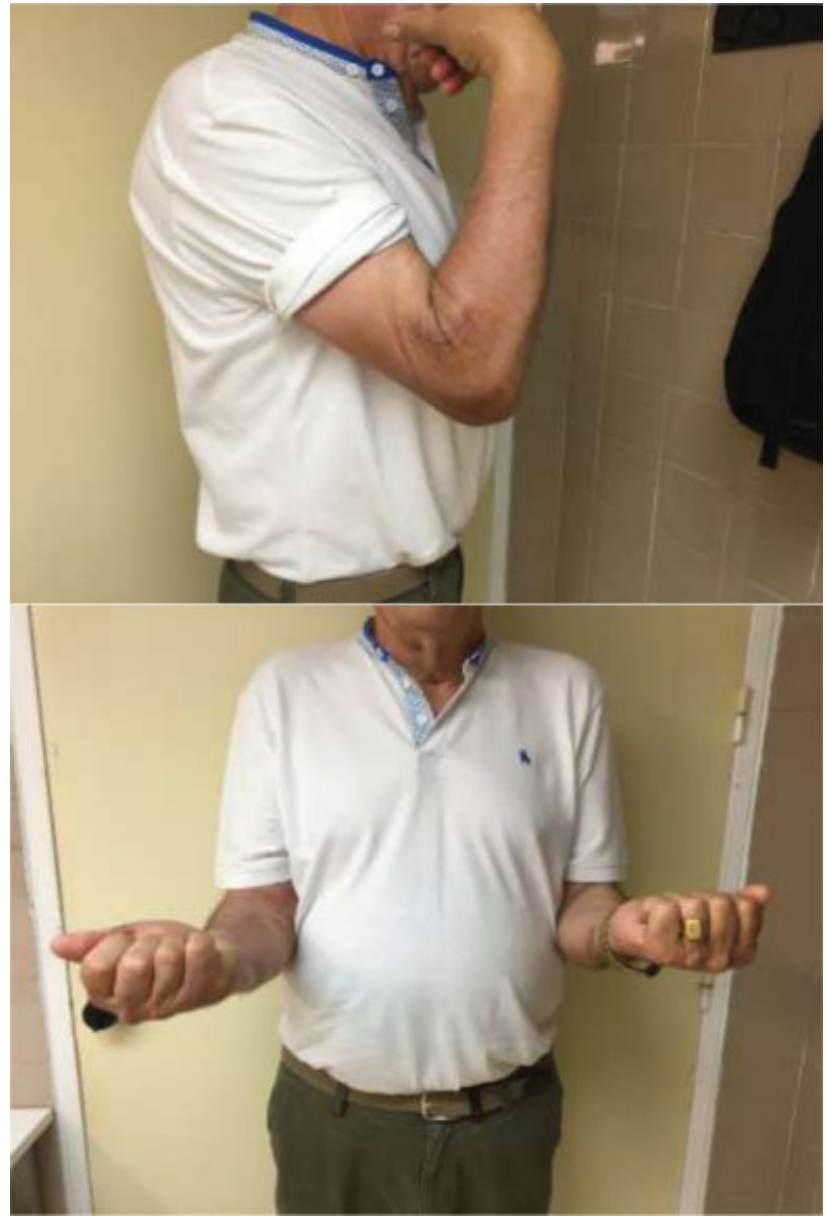

Fig. 3 Patient mobility three months after the intervention.

trauma to the hand, with radial deviation and a partially extended elbow; this resulted in a combined lesion mechanism of valgus, supination and axial compression, leading to the rupture of the lateral structures of the elbow and posterior olecranon translation, followed by pronation and consequent interposition of the distal biceps tendon. Distally-transmitted forces resulted in a diaphyseal radial fracture, as opposed to stage- 3 complete elbow dislocations, in which forces spread to the medial and anterior structures, injuring the joint capsule and the medial collateral ligament.

Most authors ${ }^{4,7}$ recommend closed reduction of the elbow with open reduction and internal fixation of the radial shaft fracture to treat these injuries. Few publications address the conservative treatment of these conditions, including a report from Beach and Hewson, ${ }^{1}$ who, in 1966 , described the case of an 87-year-old patient who was managed conservatively, probably due to comorbidities.

Focusing on the surgical treatment of similar injuries, Domingo et al. ${ }^{4}$ and Soon et al. ${ }^{6}$ presented several cases with persistence of radial head dislocation after osteosynthesis of the radius fracture, requiring a lateral approach and lateral collateral ligament repair to regain congruence. However, none of them presented an interposed biceps tendon. When discussing the need for repair of the radial collateral ligament, some authors, such as Ramesh et al. ${ }^{7}$ and Jeong et al., ${ }^{8}$ propose an initial surgical repair to avoid prolonged 


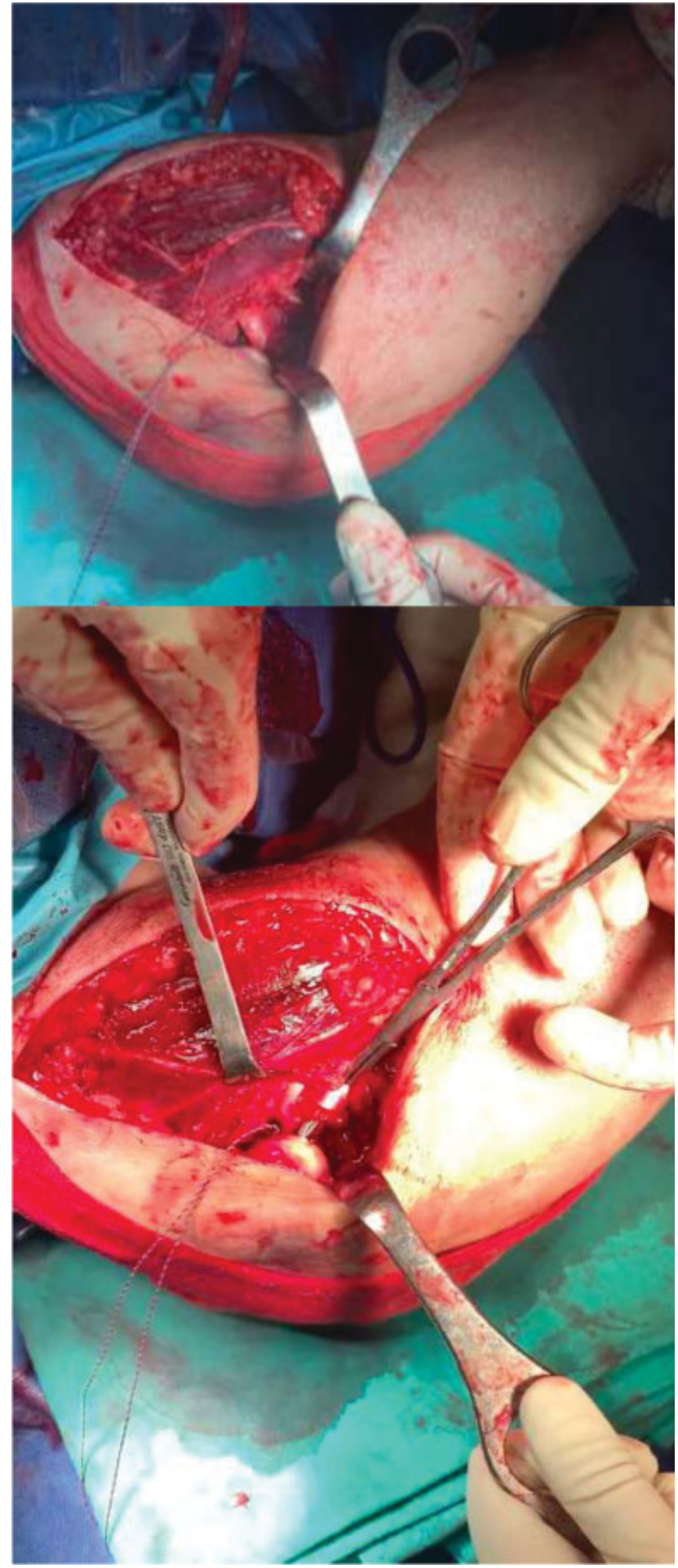

Fig. 4 Dislocated radial head and biceps tendon interposed surrounding the radial head (grasped with a mosquito forceps).

immobilization and early rehabilitation. Like us, other authors $^{9}$ believe that, if a stable reduction of the elbow is achieved after reduction of the radial head, there is no clear indication for surgical repair of the radial collateral ligament. In our case, closed reduction of the radial head was not possible due to the interposition of the long head of the biceps around the neck of the radius, a fact never discussed in adults so far in literature.

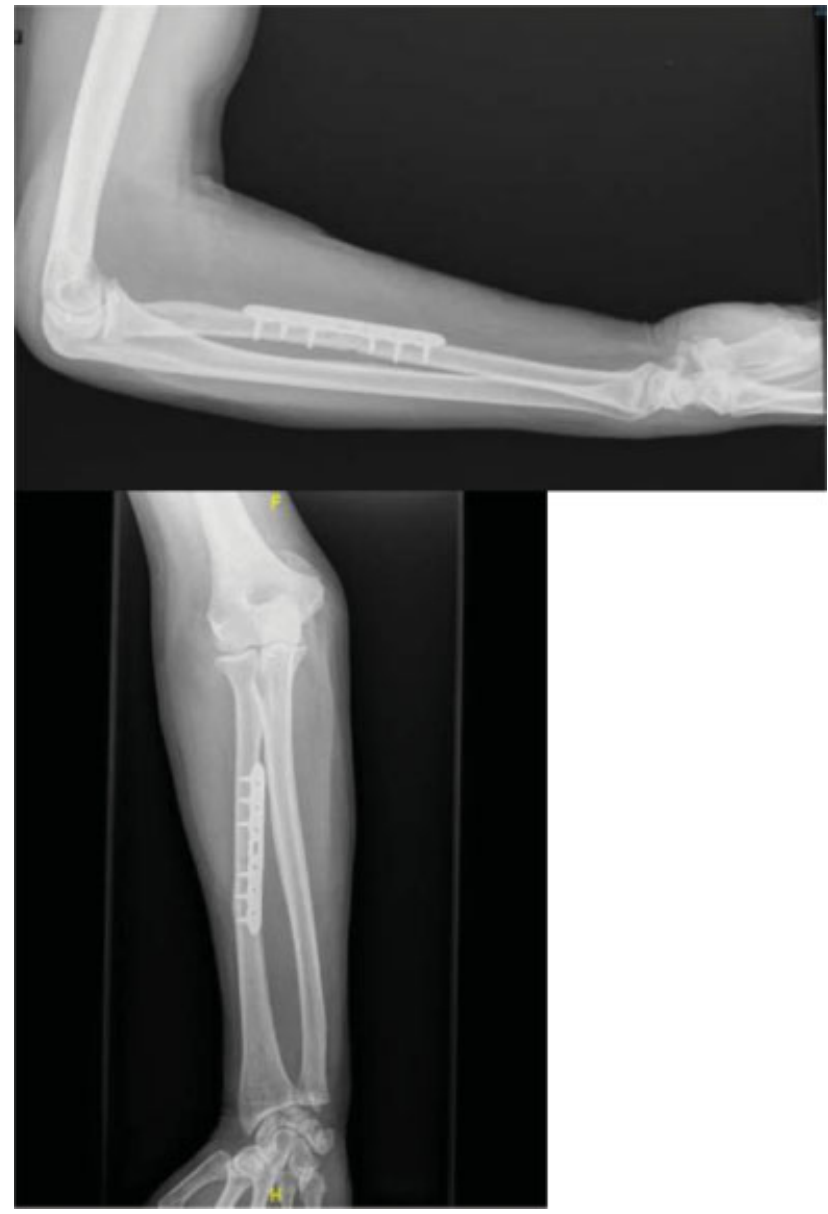

Fig. 5 Osteosynthesis of the radius shaft fracture with a 3.5-mm anteroposterior and lateral locking compression plate.

Most cases described ${ }^{9,10}$ in the literature with an irreducible dislocation of the radial head affect children and result from the interposition of soft tissues, such as a groove at the joint capsule level or even a ruptured annular ligament.

The production mechanism, described by Sasaki et al., ${ }^{11}$ consists of a fall with the hand in hyperextension and supination that causes dislocation of the radial head followed by forearm hyperpronation, which accounts for the interposition of the biceps tendon around the radial neck, preventing its correct reduction. Early diagnosis is critical for the good evolution of these injuries; otherwise, more aggressive surgeries, including tenotomies, reclamping and shortening osteotomies, are required. ${ }^{10}$

The diaphyseal radial fracture associated with a posterior elbow dislocation and an anteromedial dislocation of the radial head due to interposition of the biceps tendon is extremely rare. No other cases in adult patients were found in the literature. Therefore, we consider the case herein reported interesting, so that our colleagues may consider this possibility in the event of irreducible radial head dislocations.

\section{Conflict of Interests}

The authors have no conflict of interests to declare. 


\section{References}

1 Beach PM Jr, Hewson JS. Elbow dislocation with comminuted fracture of the proximal radial shaft. Thoughts on the mechanism. Am J Surg 1966;112(06):941-942

2 Mehara AK, Bhan S. Ipsilateral radial head dislocation with radial shaft fracture: case report. J Trauma 1993;35(06): 958-959

3 Wong-Chung J, Jahromi I, Aradi AJ. Fracture of the upper radius with ipsilateral dislocations of the elbow and superior radio-ulnar joints. A case report. Int Orthop 1998;22(01):62-64

4 Domingo A, Fernández-Valencia JA, Saz L, Prat S, Arandes JM. Elbow dislocations associated with ipsilateral radial shaft fractures: a case report and review of the literature. J Trauma 2008;64 (01):221-224

5 Dürig M, Gauer EF, Müller W. Die operative Behandlung der rezidivierenden und traumatischen Luxation des Ellenbogengelenkes nach Osborne und Cotterill. Arch Orthop Unfallchir 1976; 86(02):141-156
6 Soon JC, Kumar VPSK, Satkunanartham K. Elbow dislocation with ipsilateral radial shaft fracture. An unusual outcome. Clin Orthop Relat Res 1996;(329):212-215

7 Ramesh S, Lim YJ. Complex elbow dislocation associated with radial and ulnar diaphyseal fractures: a rare combination. Strateg Trauma Limb Reconstr 2011;6(02):97-101

8 Jeong WK, Oh JK, Hwang JH, Hwang SM, Lee WS. Results of terrible triads in the elbow: the advantage of primary restoration of medial structure. J Orthop Sci 2010;15(05):612-619

9 Veenstra KM, van der Eyken JW. Irreducible antero-medial dislocation of the radius: A case of biceps tendon interposition. Vol. 64, Acta Orthopaedica. Informa Healthcare; 1993:224-5

10 Yoshihara Y, Shiraishi K, Imamura K. Irreducible anteromedial dislocation of the radial head caused by biceps tendon clinging around the radial neck. J Trauma 2002;53(05):984-986

11 Sasaki K, Miura H, Iwamoto Y. Unusual anterior radial head dislocation associated with transposed biceps tendon: a case report. J Shoulder Elbow Surg 2006;15(06):e15-e19 